\title{
Gender Differences in the Associations Between Health Literacy and Medication Adherence in Hypertension: A Population-Based Survey in Heris County, Iran
}

This article was published in the following Dove Press journal:

Vascular Health and Risk Management

\author{
Haleh Heizomi (D)' \\ Zeynab Iraji $\mathbb{D}^{2}$ \\ Rogayeh Vaezi \\ Devender Bhalla ${ }^{3-5}$ \\ Donald E Morisky (D) ${ }^{6}$ \\ Haidar Nadrian (D) ${ }^{1,7}$ \\ 'Department of Health Education and \\ Promotion, Faculty of Health, Tabriz \\ University of Medical Sciences, Tabriz, \\ Iran; ${ }^{2}$ Department of Statistics and \\ Epidemiology, Tabriz University of \\ Medical Sciences, Tabriz, Iran; ${ }^{3}$ Pôle \\ Universitaire Euclide, Intergovernmental \\ UN Treaty 49006/49007®, Bangui, \\ Central African Republic; ${ }^{4}$ Iranian \\ Epilepsy Association $®$, Tehran, Iran; \\ ${ }^{5}$ Nepal Interest Group of Epilepsy and \\ Neurology (NiGEN), Kathmandu, Nepal; \\ ${ }^{6}$ Department of Community Health \\ Sciences, UCLA Fielding School of Public \\ Health, Los Angeles, CA, USA; ${ }^{7}$ Social \\ Determinants of Health Research Center, \\ Tabriz University of Medical Sciences, \\ Tabriz, Iran
}

Objective: We examined the gender-based associations of health literacy (HL) with selfreported medication adherence (MEDA) among patients with primary hypertension (pHTN). Patients and Methods: The subjects were recruited from the general population through all health centers of the Heris county, east Azarbaijan. They were to be adults (30+ years age), with pHTN of any stage, of any gender, and without comorbid illness. All underwent detailed face-toface interview. We used valid questionnaires for HL and MEDA. Hierarchical regression was done to establish the association between MEDA, socio-demographic variables, and nine HL domains by gender. Other statistical procedures were also done.

Results: A total of 300 (48.6\% males, mean age: $56.7 \pm 9.3)$ subjects participated; $43.0 \%$ were uneducated, $73.0 \%$ had moderate socioeconomic status, $68.0 \%$ had poor HL, and $7.0 \%$ maintained high adherence. Men were better in reading skills $(\mathrm{p}=0.002)$, and accessing $(p=0.01)$ and using $(p=0.02)$ health information, but women were better in health knowledge $(\mathrm{p}=0.004)$. The average regression estimate ( \pm standard deviation) between HL and MEDA was $0.37 \pm 0.09$, lower among men $(0.361 \pm 0.11)$ than women $(0.396 \pm 0.08), p=0.003$. Upon hierarchical regression, the association between HL and MEDA was significant for communication and decision-making skills alone among both men $(34.5 \%)$ and women $(40.6 \%)$, individually.

Conclusion: HL had substantial association with MEDA among those with HTN, for both men and women, particularly the communication and decision-making. With considerations on gender differences, this association should be confirmed through interventional studies to help make HL a formal mitigating strategy for MEDA and other public health goals.

Keywords: medication adherence, health literacy, hypertension, gender

\section{Introduction}

Hypertension (HTN) is a major risk factor of cardiovascular disease (CVD), which is the leading cause of morbidity and mortality, worldwide. ${ }^{1}$ It causes about four million deaths every year and one in every eight deaths worldwide. ${ }^{2}$ The importance of HTN can be understood from a simple example that a mere ten-point increase in the diastolic pressure above $115 / 75 \mathrm{mmHg}$ can double the risk of CVD and cerebrovascular disorders such as the stroke. ${ }^{1}$

Despite the risk of such fatal consequences, the severity of HTN is not reflected in patient's attitudes towards medication adherence. For instance, in Saudi Arabia,
Correspondence: Haidar Nadrian Department of Health Education and Promotion, Faulty of Health, Tabriz University of Medical Sciences, Attare-Neyshabouri Street, Tabriz, Iran Tel +989181734596

Email haidarnadrian@gmail.com 
merely $6.2 \%$ subjects maintain high adherence to antihypertension medications (AHMs), ${ }^{3}$ which is critical if one wishes to obtain optimal and sustained control over their HTN. In the US, half of those affected would discontinue their medication within one year itself. $^{4}$ Moreover, people may find hard to accept that HTN may lead to serious consequences. ${ }^{5}$ Thus, it is clear that the patient's own attitude and practice towards HTN and its treatment remains fairly compromised. ${ }^{5}$ The importance of patient's own role in adherence can also be understood from the definition of adherence, which is defined as "the degree to which the person's behavior corresponds with the agreed recommendations from a health care provider."

One of the ways to ameliorate the patient's own attitude and practice towards HTN and its treatment is the level of health literacy (HL). Health literacy is understood as the:

cognitive and social skills which determine the motivation and ability of individuals to gain access to, understand and use information in ways which promote and maintain their good health ${ }^{7}$

This way, HL goes beyond a narrow concept of health education and individual behavior-oriented communication, and addresses the environmental, political, and social factors that determine health. HL is not a personal characteristic but a key component that may help achieve various preventative and therapeutic goals. ${ }^{8}$ For instance, inadequate $\mathrm{HL}$ can postpone the diagnosis, ${ }^{9}$ weaken the self-care ability, ${ }^{10}$ and enhance the risk for different morbidities and mortality. ${ }^{11}$ On the other hand, health literate subjects are better aware of their hypertensive state ${ }^{12}$ and are more likely to achieve blood pressure control. ${ }^{13}$

Gender differences in HL and MEDA have been investigated in academic literature and controversial findings are reported. Although certain studies reported no significant difference in $\mathrm{MEDA}^{14}$ and HL, ${ }^{15}$ by gender, a number of previous studies have claimed gender differences. For instance, in a previous study, men were reported to be more likely to adhere to medications. ${ }^{16}$ Some other studies reported greater level of $\mathrm{MEDA}^{17,18}$ and $\mathrm{HL}^{19}$ among women. However, only few studies have examined the association of HL with self-management goals such as good adherence to AHMs. ${ }^{5}$ This lack is more so in low-middle income populations where the health system and cultural beliefs differ. Thus, considering the fact that there are effective AHMs available, we think that assessing the issue of medication adherence through HL could be integral for better management of HTN. Therefore, this cross-sectional population-based study was undertaken to determine, as our primary objective, the characteristics related to health literacy among hypertensive subjects, and its relationship with the adherence to antihypertensive medications in an adult population of East Azarbaijan. Our secondary objective was to determine the validity and factor structure of four-item Morisky, Green, and Levine (MGL) scale.

\section{Methods}

\section{Participants and Sampling}

In this cross-sectional study, we systematically collected data from among the patients of primary hypertension (pHTN) who were residents of Heris county of East Azerbaijan, Iran. The patients were recruited (from May to July 2018) through structured household files of all existing health centers of our study setting. In our country, all health centers are required, by law, to maintain a monthly updated household file for each household. The subjects were to have confirmed pHTN ie, systolic and/or diastolic BP $>120 / 80 \mathrm{mmHg}$ on two separate occasions in a seated position (Based on the Eighth Joint National Committee (JNC 8), ${ }^{2}$ have been diagnosed in the last six months, be of any gender and of at least 30 years of age, resident of study areas since at least six months, do not possess comorbidities including diabetes mellitus, rheumatoid arthritis, osteoarthritis, coronary heart disease, and hyperlipidemia (as the research team assumed that hypertensive patients with such comorbidities may have a different pattern of HL and MEDA), and be willing and able to participate, independently. As all patients were routinely visited by a physician in the health centers, all were on AHM. All data were collected through structured questionnaires in an oral face-to-face interview by a single field staff to avoid inter-observer bias.

\section{Measures}

HL was determined through a validated Iranian Health Literacy Questionnaire (IHLQ). ${ }^{20}$ This questionnaire consists of nine domains: two binary sub-scales of health information (HI) access and HI use, and three sub-scales of reading skills, comprehension skills, accurate assessment, and judgment skills that are scored on a 4-point scale (1-4), and four sub-scales of communication and decision-making skills, health knowledge, individual empowerment, and social empowerment that are scored on a 3-point scale (1-3). The final score of HL was based on a scale of zero 
to twenty, in which HL was categorized as poor (score of $<10$ ), moderate (score of 10-14), and adequate (score of $>14$ ), as presented in the validation study. ${ }^{20}$

The medication adherence (MEDA) to pharmacotherapy was determined by using the four-item Morisky, Green, and Levine (MGL) scale, ${ }^{21}$ which includes four questions with yes/no response format. The MGL scale is scored from 0 to 4 between low adherence (score $0-1$ ), moderate adherence (score 2-3) and high adherence (score 4). ${ }^{21,22}$ The socio-demographic characteristics of our participants were determined on seven items: age, grade of birth, number of family members, number of children, level of education (Illiterate/Elementary/High school/Diploma/University), medical services insurance (Yes/No), and family socio-economic status (fSES). The family socio-economic status was determined by using Persian family affluence scale (FAS). ${ }^{23}$ This scale comprises five different properties: family car ownership, computer and laptop ownership, number of rooms excluding kitchen and bathrooms, number of telephones, and having or not having unshared bedroom. This scale has an overall score range of $0-13$, and categorized as low (score of $0-4$ ), moderate (score of 5-8) and high (score of 9-13).

\section{Statistics}

By using an expected correlation of 0.5 between HL and MEDA, $80.0 \%$ sample power, standard deviation (SD) of 2.0, two-sided $5.0 \%$ alpha, we expected to require a total of 126 subjects. All data were entered into MS-Excel and was analyzed by using SPSS v16. Descriptive data were presented in terms of number, frequency, mean, and SD, as deemed suitable. Where necessary, the means and proportions were compared by using $\mathrm{t}$ and $\mathrm{z}$ tests. The normality of the quantitative variables was assessed by one-sample Kolmogorov-Smirnov (K-S) test. In order to assess the associations between HL and MEDA over the influence of other parameters, a hierarchical multiple linear regression was conducted for both men and women, separately. According to their natures, the predictors for the outcome variable were classified into two different blocks: (a) socio-demographic characteristics block that included age, number of children, educational status, residency, socio-economic status, and family size, and (b) HL block that included nine domains of the HL scale.

As the MGL scale has not been validated in Persian, the exploratory factor analysis (EFA) and confirmatory factor analysis (CFA) were applied to determine the construct validity of the scale. The sampling adequacy was considered by Kaiser-Meyer-Olkin (KMO) test, as KMO more than 0.7 was considered to be appropriate. Principal component analysis with varimax rotation was used to conduct factor analysis. In addition, the data correlation matrix was tested with Bartlet's test of sphericity with a significance level of $5 \%$. The loading values were considered to be at least 0.3 as acceptable. The eigenvalues higher than 1 were the basis for determining the factor. The most common indicators of goodness of fit were provided for the model and evaluated using CFA. The normal distribution of the data was based on the skewness and kurtosis measure ${ }^{24}$ followed by Chi-square test for goodness of fit (standard values $>0.9$ ), root mean square error root index (good: $<0.08$, moderate: $0.08-0.1$, and weak: $>0.1$ ), comparative fit index (CFI) (standard values $>0.9$ ), normed fit index (NFI) (standard value $>0.9$ ), adjusted goodness of fit index (standard values $>0.8$ ), and finally, the Normed Chi-Square (CMIN/DF). ${ }^{25}$ The internal consistency of our FAS was also determined by estimating Cronbach alpha. Lastly, informed consent was taken from all participants prior to their participation. Ethics approval was obtained from the Institutional review Board of the Tehran University of Medical Sciences.

\section{Results}

\section{Socio-Demographic Details}

A total of 520 subjects with pHTN were identified; of which 220 were excluded from participation because 160 subjects had other comorbid chronic illnesses, 42 subjects refused to participate, and 18 subjects were inaccessible. Thus, a total of $300(n=146,48.6 \%$ males) subjects participated in our survey. The mean age of our participants was 56.7 (SD 9.3, range 30-92) years. A total of 129 (43.0\%) subjects were illiterate, $219(73.0 \%)$ subjects had moderate fSES, and nearly everyone $(\mathrm{n}=295,98.3 \%)$ had medical services insurance. With respect to HL, 198 (68.0\%) subjects had poor HL, 44 (14.7\%) subjects had moderate HL, and 58 (19.3\%) subjects had adequate HL. With respect to MEDA, merely $21(7.0 \%)$ subjects had high adherence, with no gender difference, $\mathrm{p}=0.36$. The remaining socio-demographic results are provided in Table 1.

\section{Factor Structure of the MGL and Internal Consistency of FAS}

In the EFA, the KMO test for sample adequacy was 0.648 , and the result of the Bartlet's test of sphericity was statistically significant $(p<0.001)$. In the last iteration of analysis, two 
Table I Gender Differences in Medication Adherence by Socio-Demographic Characteristics of Those with Primary Hypertension

\begin{tabular}{|c|c|c|c|c|c|c|c|c|c|c|}
\hline Variable & \multicolumn{3}{|c|}{ MEDA-T (n, \%) } & \multicolumn{3}{|c|}{ MEDA-M (n, \%) } & \multicolumn{3}{|c|}{ MEDA-W (n, \%) } & P-value* \\
\hline \multicolumn{11}{|l|}{ Age } \\
\hline $\begin{array}{l}30-45 \\
46-60 \\
>60\end{array}$ & $\begin{array}{l}\mathrm{H} \\
6,24.0 \% \\
9,4.6 \% \\
6,7.6 \%\end{array}$ & $\begin{array}{l}M \\
12,48.0 \% \\
106,54.1 \% \\
32,40.5 \%\end{array}$ & $\begin{array}{l}\mathrm{L} \\
7,28.0 \% \\
81,41.3 \% \\
41,51.9 \%\end{array}$ & $\begin{array}{l}\mathrm{H} \\
2,22.2 \% \\
4,4.3 \% \\
3,6.8 \%\end{array}$ & $\begin{array}{l}M \\
4,44.4 \% \\
53,57.0 \% \\
17,38.6 \%\end{array}$ & $\begin{array}{l}\mathrm{L} \\
3,33.3 \% \\
36,38.7 \% \\
24,54.5 \%\end{array}$ & $\begin{array}{l}\mathrm{H} \\
4,33.3 \% \\
5,41.7 \% \\
3,25.0 \%\end{array}$ & $\begin{array}{l}M \\
8,10.5 \% \\
53,69.7 \% \\
15,19.7 \%\end{array}$ & $\begin{array}{l}\mathrm{L} \\
4,6.1 \% \\
45,68.2 \% \\
17,25.8 \%\end{array}$ & 0.002 \\
\hline \multicolumn{11}{|c|}{ Family size } \\
\hline $\begin{array}{l}2 \\
3 \\
4 \\
\geq 5\end{array}$ & $\begin{array}{l}2,14.3 \% \\
3,16.7 \% \\
6,5.7 \% \\
10,6.2 \%\end{array}$ & $\begin{array}{l}5,35.7 \% \\
9,50.0 \% \\
66,62.3 \% \\
70,43.2 \%\end{array}$ & $\begin{array}{l}7,0.0 \% \\
6,33.3 \% \\
34,32.1 \% \\
82,50.6 \%\end{array}$ & $\begin{array}{l}0,0.0 \% \\
1,10.0 \% \\
2,3.8 \% \\
6,7.6 \%\end{array}$ & $\begin{array}{l}2,40.0 \% \\
6,60.0 \% \\
35,67.3 \% \\
31,39.2 \%\end{array}$ & $\begin{array}{l}3,60.0 \% \\
3,30.0 \% \\
15,28.8 \% \\
42,53.2 \%\end{array}$ & $\begin{array}{l}2,22.2 \% \\
2,25.0 \% \\
4,7.4 \% \\
4,4.8 \%\end{array}$ & $\begin{array}{l}3,33.3 \% \\
3,37.5 \% \\
31,57.4 \% \\
39,47.0 \%\end{array}$ & $\begin{array}{l}4,44.4 \% \\
3,37.5 \% \\
19,35.2 \% \\
40,48.2 \%\end{array}$ & 0.120 \\
\hline \multicolumn{11}{|c|}{ Number of children } \\
\hline $\begin{array}{l}1 \\
2 \\
3 \\
\geq 4\end{array}$ & $\begin{array}{l}0,0.0 \% \\
6,6.5 \% \\
6,7.7 \% \\
9,7.9 \%\end{array}$ & $\begin{array}{l}9,60.0 \% \\
65,69.9 \% \\
33,42.3 \% \\
43,37.7 \%\end{array}$ & $\begin{array}{l}6,40.0 \% \\
22,23.7 \% \\
39,50.0 \% \\
62,54.4 \%\end{array}$ & $\begin{array}{l}0,0.0 \% \\
2,4.4 \% \\
4,11.1 \% \\
3,5.5 \%\end{array}$ & $\begin{array}{l}6,60.0 \% \\
33,73.3 \% \\
13,36.1 \% \\
22,40.0 \%\end{array}$ & $\begin{array}{c}4,40.0 \% \\
10,22.2 \% \\
19,52.8 \% \\
30,54.5 \%\end{array}$ & $\begin{array}{l}0,0.0 \% \\
4,8.3 \% \\
2,4.8 \% \\
6,10.2 \%\end{array}$ & $\begin{array}{l}3,60.0 \% \\
32,66.7 \% \\
20,47.6 \% \\
21,35.6 \%\end{array}$ & $\begin{array}{l}2,40.0 \% \\
12,25.0 \% \\
20,47.6 \% \\
32,54.2 \%\end{array}$ & 0.000 \\
\hline \multicolumn{11}{|c|}{ Educational status } \\
\hline $\begin{array}{l}\text { Illit } \\
\text { Elem } \\
\text { High } \\
\text { Dipl } \\
\text { Univ }\end{array}$ & $\begin{array}{l}5,3.9 \% \\
9,19.1 \% \\
1,3.2 \% \\
4,10.8 \% \\
2,3.6 \%\end{array}$ & $\begin{array}{l}48,37.2 \% \\
13,27.7 \% \\
13,41.9 \% \\
28,75.7 \% \\
48,85.7 \%\end{array}$ & $\begin{array}{l}76,58.9 \% \\
25,53.2 \% \\
17,54.8 \% \\
5,13.5 \% \\
6,10.7 \%\end{array}$ & $\begin{array}{l}\text { I, } 2.3 \% \\
6,20.7 \% \\
0,0.0 \% \\
2,8.0 \% \\
0,0.0 \%\end{array}$ & $\begin{array}{l}14,32.6 \% \\
7,24.1 \% \\
8,42.1 \% \\
20,80.0 \% \\
25,83.3 \%\end{array}$ & $\begin{array}{l}28,65.1 \% \\
16,55.2 \% \\
11,57.9 \% \\
3,12.0 \% \\
5,16.7 \%\end{array}$ & $\begin{array}{l}4,4.7 \% \\
3,16.7 \% \\
\text { I, } 8.3 \% \\
2,16.7 \% \\
2,7.7 \%\end{array}$ & $\begin{array}{l}34,39.5 \% \\
6,33.3 \% \\
5,41.7 \% \\
8,66.7 \% \\
23,88.5 \%\end{array}$ & $\begin{array}{l}48,55.8 \% \\
9,50.0 \% \\
6,50.0 \% \\
2,16.7 \% \\
\text { I, 3.8\% }\end{array}$ & $<0.0001$ \\
\hline \multicolumn{11}{|c|}{ Medical Services Insurance } \\
\hline $\begin{array}{l}\text { Yes } \\
\text { No }\end{array}$ & $\begin{array}{l}21,7.1 \% \\
0,0.0 \%\end{array}$ & $\begin{array}{l}\text { I49,50.0\% } \\
\text { I, 20.0\% }\end{array}$ & $\begin{array}{l}125,42.4 \% \\
4,80.0 \%\end{array}$ & $\begin{array}{l}9,6.3 \% \\
0,0.0 \%\end{array}$ & $\begin{array}{l}74,51.4 \% \\
0,0.0 \%\end{array}$ & $\begin{array}{l}61,42.4 \% \\
2,100.0 \%\end{array}$ & $\begin{array}{l}12,7.9 \% \\
0,0.0 \%\end{array}$ & $\begin{array}{l}75,49.7 \% \\
\text { I, 33.3\% }\end{array}$ & $\begin{array}{l}64,42.4 \% \\
2,66.7 \%\end{array}$ & 0.236 \\
\hline \multicolumn{11}{|c|}{ Family socio-economic status } \\
\hline $\begin{array}{l}\text { Low } \\
\text { Inter } \\
\text { High }\end{array}$ & $\begin{array}{l}0,0.0 \% \\
19,8.7 \% \\
2,3.2 \%\end{array}$ & $\begin{array}{l}2,11.1 \% \\
100,45.7 \% \\
48,76.2 \%\end{array}$ & $\begin{array}{l}16,88.9 \% \\
100,45.7 \% \\
13,20.6 \%\end{array}$ & $\begin{array}{l}0,0.0 \% \\
9,8.8 \% \\
0,0.0 \%\end{array}$ & $\begin{array}{l}2,22.2 \% \\
45,44.1 \% \\
27,77.1 \%\end{array}$ & $\begin{array}{l}7,77.8 \% \\
48,47.1 \% \\
8,22.9 \%\end{array}$ & $\begin{array}{l}0,0.0 \% \\
10,8.5 \% \\
2,7.1 \%\end{array}$ & $\begin{array}{l}0,0.0 \% \\
55,47.0 \% \\
21,75.0\end{array}$ & $\begin{array}{l}9,100.0 \% \\
52,44.4 \% \\
5,17.9 \%\end{array}$ & $<0.0001$ \\
\hline
\end{tabular}

Note: ${ }^{p}$-values represent gender differences in MEDA by socio-demographic variables.

Abbreviations: Elem, elementary schooling; Dipl, diploma; High, high school; H/M/L indicates high, medium, and low adherence; Illit, illiterates; Inter, intermediate family socio-economic status; MEDA, medication adherence; M, men; Univ, University; W, women.

distinctive factors were extracted. These two factors explained $80 \%$ of total variance between the items. However, in the CFA, item number 4 was not loaded and thus the model of CFA for the scale did not fit. As the number of items for the scale was low and, given that previous studies on the scale confirmed the four items, the research team decided not to delete the fourth item. Inspecting the Cattell's scree test, the possibility to extract one factor was also indicated. Therefore, we conducted another run of factor analysis with one factor. Finally, we distinguished the one-factor solution as the most distinct pattern for factor loadings. This solution explained $55 \%$ of cumulative variance. In the CFA, Figure 1, the results of Chi-square test for goodness of fit were obtained first (dif $\left.=2, \chi^{2}=3.055, \mathrm{p}<0.0001\right)$. All indices, including $\mathrm{RMSEA}=0.042, \mathrm{SRMR}=0.025, \mathrm{CFI}=0.997, \mathrm{TLI}=0.992$ confirmed the fitting fit for the final model. The overall Cronbach alpha for our FAS was estimated to be 0.65 .

\section{Main Findings}

The HL was overall poor among our participants, and the overall mean HL score was 8.948 (SD 5.54), which was higher among men (9.423, SD: 5.70, 95\% CI: 8.55-9.73) than women (8.495, SD: 5.34 95\% CI: 8.23-8.81), $\mathrm{p}=0.07$. Among all domains, HL was moderate for comprehension (for overall and for men) and accurate assessment (overall and for both genders), and HL was adequate for health 


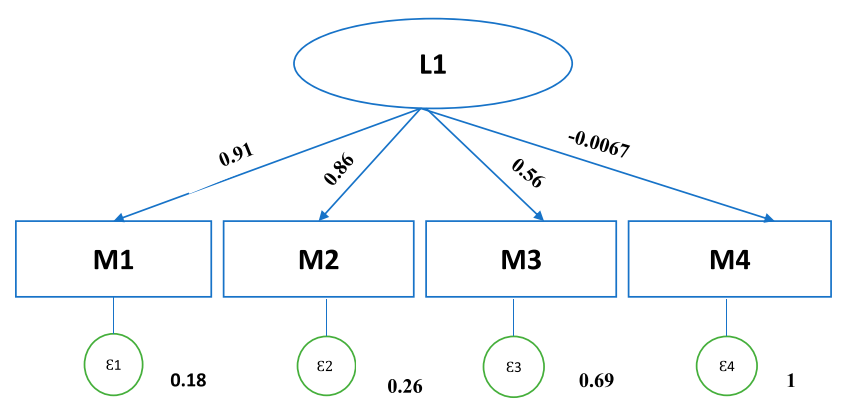

Figure I Factor loadings in one component model from confirmatory factor analysis of medication adherence scale.

knowledge (overall and for both genders), Table 2 . Between men and women, the mean scores of individual HL domains were descriptively higher for men than women, except health knowledge, while the group mean difference was statistically significant for $\mathrm{HI}$ access $(\mathrm{p}=0.01)$ and use $(\mathrm{p}=0.02)$, reading skills $(\mathrm{p}=0.002)$, and health knowledge $(\mathrm{p}=0.004)$ alone, Table 2.

With regards to the association between HL and MEDA, the mean overall regression parameter estimate was 0.373 (SD 0.09, 95\% CI: 0.369-0.381), which was lower among men $(0.36$, SD $0.11,95 \%$ CI: $0.34-0.37)$ than women $(0.39$, SD 0.08 , 95\% CI: 0.38-0.41), $\mathrm{p}=0.003$. Domain-wise, overall and for men, their association was found to be maximum for communication and decision-making skills and lowest for health knowledge. For women, this association was highest for communication and decision-making skills and lowest for social empowerment. Upon hierarchical regression, the association between HL and MEDA was significant for communication and decision-making skills alone for both men and women, with no significant difference between the two regression parameter estimates of men and women, $p=0.40$. For men, no sociodemographic factor yields any association with MEDA, while for women, the high number of children and low fSES also accounted for association between HL and MEDA, Table 3. Education did not cause an effect when HL domains were entered in the model for association of HL with MEDA, Table 3. Lastly, Cronbach's alpha for all HL constructs was at least 0.76, except for health knowledge; which means an acceptableexcellent internal consistency of our questionnaire, Table 2.

\section{Discussion}

We performed this population-based survey in East Azarbaijan to systematically determine, in principle, the gender-specific relationship of HL with MEDA among those with pHTN after accounting for suitable sociodemographic variables. In addition, we determined the construct validity of the Persian MGL scale, which was inexistent previously, and also the internal consistency of FAS scale. This way, our study is one of the few studies from our region to have addressed associations between HL and MEDA, and also one of the firsts to have provided the factor structure of MGL scale.

Our study procedures were fairly appropriate. For instance, our sample size was a calculated one and was estimated for a correlation of 0.5 at $80 \%$ power. The participants were recruited through all health center areas which covers the whole population of our study setting. The questionnaires that we used are scientifically valid. For instance, our HL questionnaire had nine domains covering functional, interactive, and critical HL skills. Our MGL questionnaire is also among the most widely used tools for assessing MEDA,

Table 2 Association of Health Literacy Domains with Medication Adherence

\begin{tabular}{|l|l|l|l|l|l|l|l|}
\hline \multirow{2}{*}{ Health Literacy Variable } & \multirow{2}{*}{$\boldsymbol{\alpha}$} & \multicolumn{2}{l|}{ Mean (SD) } & \multicolumn{2}{l|}{ MEDA } \\
\cline { 3 - 8 } & & $\mathbf{T}$ & $\mathbf{M}$ & $\mathbf{W}$ & T & M \\
\hline HI Access & 0.76 & $9.4(6.0)$ & $10.2(6.4)$ & $8.6(5.5)$ & $0.29^{*}$ & $0.29^{*}$ & $0.33^{*}$ \\
HI Use & 0.77 & $9.6(5.8)$ & $10.3(6.3)$ & $8.9(5.3)$ & $0.34^{*}$ & $0.29^{*}$ & $0.40^{*}$ \\
Reading skills & 0.97 & $7.0(7.6)$ & $8.3(7.6)$ & $5.8(7.4)$ & $0.45^{*}$ & $0.47^{*}$ & $0.44^{*}$ \\
Comprehension skills & 0.95 & $10.0(5.0)$ & $10.4(5.0)$ & $9.5(4.9)$ & $0.42^{*}$ & $0.46^{*}$ & $0.38^{*}$ \\
AAJS & 0.94 & $10.6(5.1)$ & $11.1(5.2)$ & $10.1(5.1)$ & $0.43^{*}$ & $0.44^{*}$ & $0.43^{*}$ \\
CDMS & 0.90 & $9.7(5.8)$ & $10.0(5.8)$ & $9.5(5.9)$ & $0.53^{*}$ & $0.53^{*}$ & $0.54^{*}$ \\
Health Knowledge & 0.41 & $14.7(2.0)$ & $14.4(2.0)$ & $15.0(2.0)$ & $0.24^{*}$ & $0.20^{*}$ & $0.28^{*}$ \\
PE & 0.93 & $4.3(6.0)$ & $4.6(6.3)$ & $4.0(5.6)$ & $0.37^{*}$ & $0.30^{*}$ & $0.44^{*}$ \\
Social empowerment & 0.87 & $4.9(6.2)$ & $5.2(6.3)$ & $4.6(6.0)$ & $0.26^{*}$ & $0.25^{*}$ & $0.27^{*}$ \\
\hline
\end{tabular}

Note: ${ }^{*}$ < $<0.01 ; \alpha$ : Cronbach alpha.

Abbreviations: AAJS, accurate assessment and judgment skills; CDMS, communication and decision-making skills; HI, health information; M, men; MEDA, medication adherence; PE, personal empowerment; SD, standard deviation; T, total of men and women; W, Women. 
Table 3 Hierarchical Regression Analysis to Predict Medication Adherence

\begin{tabular}{|c|c|c|c|c|}
\hline \multirow{2}{*}{$\begin{array}{l}\text { Outcome Variable: } \\
\text { Medication Adherence }\end{array}$} & \multicolumn{2}{|l|}{ Men } & \multicolumn{2}{|l|}{ Women } \\
\hline & $\begin{array}{l}\text { Model } \\
\text { I, } \beta\end{array}$ & $\begin{array}{l}\text { Model } \\
2, \beta\end{array}$ & $\begin{array}{l}\text { Model } \\
\text { I, } \beta\end{array}$ & $\begin{array}{l}\text { Model } \\
2, \beta\end{array}$ \\
\hline \multicolumn{5}{|l|}{ Block I: } \\
\hline Age & -0.027 & 0.013 & -0.037 & 0.000 \\
\hline Number of children & 0.147 & 0.073 & 0.145 & $0.198^{*}$ \\
\hline Educational status & $-0.293^{* *}$ & 0.244 & $-0.220^{* *}$ & 0.322 \\
\hline Family size & -0.039 & 0.001 & 0.062 & -0.028 \\
\hline Residency & -0.090 & -0.035 & 0.006 & -0.003 \\
\hline Socio-economic Status & -0.082 & -0.042 & $-0.347^{* *}$ & $-0.213^{*}$ \\
\hline \multicolumn{5}{|l|}{ Block 2: } \\
\hline Health information access & & 0.092 & & 0.239 \\
\hline Health information use & & 0.136 & & -0.147 \\
\hline Reading skills & & -0.295 & & -0.294 \\
\hline Comprehension skills & & -0.231 & & 0.248 \\
\hline AAJS & & 0.101 & & -0.049 \\
\hline CDMS & & $-0.545^{* *}$ & & $-0.610 * *$ \\
\hline Health Knowledge & & -0.037 & & -0.067 \\
\hline Personal empowerment & & 0.054 & & -0.171 \\
\hline Social empowerment & & 0.078 & & 0.181 \\
\hline $\mathrm{R}^{2}$ & 0.186 & 0.345 & 0.282 & 0.406 \\
\hline Cumulative $\mathrm{R}^{2}$ & 0.186 & 0.531 & 0.282 & 0.688 \\
\hline$P$ value & $<0.001$ & $<0.001$ & $<0.001$ & $<0.001$ \\
\hline
\end{tabular}

Notes: ${ }^{*}$-value $=$ less than $0.05 ;{ }^{*}$ p-value $=$ less than 0.01 .

Abbreviations: AAJS, accurate assessment and judgment skills; CDMS, communication and decision-making skills.

including for those with low literacy. ${ }^{26}$ Significant genderbased differences in MEDA by socio-demographic characteristics (Table 1) as well as the associations between the HL constructs and MEDA (Table 2) may be considered as findings to confirm the construct validity (the CFA results) of MGL. Another questionnaire that we used was FAS, to objectively determine fSES, which also had an acceptable internal consistency.

Moving further, for those with HTN, lifetime and persistent uptake of AHMs is one of the most effective ways to achieve desired therapeutic goals. However, this kind of dedicated uptake is rarely seen, ${ }^{27}$ for most part, due to patients' own faults. ${ }^{28}$ For instance, those affected "do not have the time to take prescribed AHMs", or, have "a lot of important tasks to do", or, AHMs prohibit their "life's pleasures" and interfere in "personal liberty". ${ }^{29}$ In our population as well, only $7.0 \%$ subjects had maintained high adherence, despite being affected and despite having good fSES (ie, $94.0 \%$ subjects) and medical insurance cover (ie, $98.3 \%$ subjects) that reimburses their costs. Thus, cultivating good attitude and practice among patients is the foremost necessity to meet good adherence, blood pressure control, and better reduction of public health burden of HTN. ${ }^{27,28}$

Also, the majority $(66.0 \%)$ of our subjects had low HL (Table 4); meaning 34.0\% subjects with moderate-to-adequate HL. A direct comparison with other studies may not be entirely meaningful, given the differences in the type of health problem, nature of health system, socio-cultural character of the population, methodological issues, etc. However, our frequencies are better than developed countries ${ }^{30}$ and those from Iran, ${ }^{31}$ but not always. ${ }^{12}$ The population-to-population difference in the frequency of $\mathrm{HL}$ could be due to the use of different questionnaires. For instance, the study that reported better frequency of $\mathrm{HL}$ than ours ${ }^{12}$ had poorly validated their questionnaire and had two HL domains only. In contrast, we covered nine HL domains. Other reasons for such difference can be rural-urban variation in the study setting, or, socio-cultural character of the population. For instance, in Middle-Eastern and similar cultures, the families are one "collective" unit, so, the $\mathrm{HL}$ of one member may possibly influence that of other member. ${ }^{32}$ In our population as well, $89.33 \%$ individuals had at least four members in their family.

Moreover, those with poor HL and poor maintenance in health promotion programs often include the ones who are less educated, ${ }^{33}$ poorer, older and ethnically diverse. ${ }^{34}$ Much of this matches fairly well with our results. For instance, a fairly large proportion of our subjects were uneducated (Table 1), predominantly women, which may explain that the maximum difference between men and women was in the reading skills than all other HL domains. Moreover, the mean HL of those with low ISES differed significantly from those with moderate-tohigh fSES, Table 1. Furthermore, about $92.0 \%$ subjects were above the age of 46 years, which is the time when HL starts to

Table 4 Health Literacy by Adherence and Gender Among Hypertensive Patients

\begin{tabular}{|l|l|l|l|l|}
\hline Level of HL & $\mathbf{N}(\%)$ & MEDA & Men- N (\%) & Women- N (\%) \\
\hline Low & \multirow{2}{*}{ 998(66.0) } & High & $6(6.7)$ & $\begin{array}{l}7(6.4) \\
\end{array}$ \\
& & Moderate & $29(32.6)$ & $43(39.4)$ \\
& & Low & $54(60.7)$ & $59(54.1)$ \\
\hline Moderate & \multirow{2}{*}{$4(14.7)$} & High & $2(7.4)$ & $2(11.8)$ \\
& & Moderate & $18(66.7)$ & $9(52.9)$ \\
& & Low & $7(25.9)$ & $6(35.3)$ \\
\hline \multirow{2}{*}{ Enough } & \multirow{2}{*}{$8(19.3)$} & High & $1(3.3)$ & $3(10.7)$ \\
& & Moderate & $27(90.0)$ & $24(85.7)$ \\
& & Low & $2(6.7)$ & $1(3.6)$ \\
\hline
\end{tabular}

Note: Chi-square Test.

Abbreviations: $\mathrm{HL}$, health literacy; MEDA, medication adherence. 
decline because of impending cognitive and psychosocial challenges. ${ }^{35}$

In the present study, HL was poor among more women than men ( $70.7 \%$ vs $60.9 \%, \mathrm{p}=0.036$, respectively). This could possibly be because more women were uneducated than men (Table 1), and the mean reading skills and access and use of $\mathrm{HI}$ was lower among women than men (Table 1). Despite this, the health knowledge was significantly higher among women than men, Table 2 . These results should not surprise us because even the uneducated subjects have been seen to possess high knowledge ${ }^{36}$ ), but something that does not translate into better health practice or HTN outcomes, ${ }^{36}$ as it was in our population. Low use and access of HI among women is likely to be due to poor HI seeking by them, for instance, due to inadequate support from the health-care system, shame and embarrassment, costs, wrong ideas and beliefs, and inadequate HL. ${ }^{37}$ For instance, "Sometimes I think, if I had not asked about it, it would not happen to me". ${ }^{37}$ In other cultures also, women are less involved in seeking $\mathrm{HI},{ }^{38}$ possibly because of poor access to internet, lack of credible education sources to obtain information in simple language, ${ }^{39}$ or, difficulty with complex medical and English terms during consultation. ${ }^{40}$

Moving further, those with poor MEDA was fairly high in our population $(\mathrm{n}=129,43.0 \%)$, with no difference between men $(n=63,43.1 \%)$ and women $(n=66,42.8 \%$, $\mathrm{p}=0.47$ ). This result is both similar ${ }^{41}$ and different ${ }^{42}$ to other studies, and sometimes much higher than ours. ${ }^{43}$ The possible reason for this, despite having the medical insurance, could be the indirect costs, ${ }^{37}$ or, poor attitude towards AHMs, or methodological reasons. ${ }^{44}$ For instance,

I know a woman who may feel sick once or twice daily, and she has many health questions, but she says if she was to go to a general physician and not a specialist, it would cost her 10-12 thousand Tomans, plus her taxi fare and medication cost, so she cannot afford all that. ${ }^{37}$

Moving further, we found a substantial relationship between MEDA and HL, for both men and women, and independent of socio-demographic characteristics, especially for men. Few have examined this association, mostly in specific populations, ${ }^{45}$ and the results are both negative ${ }^{46}$ and positive, which shows that HL does not just have a direct effect on MEDA but is also its mediator. ${ }^{47}$ The unclear relationship between the two is mostly due to the dearth of interventional studies that are more suited to determine this kind of relationship better. For women, MEDA was associated with high number of children and low fSES, Table 3. These results are also not surprising because MEDA may reduce with increasing number of family members ${ }^{48}$ and with poor SES. ${ }^{14,36,49}$ An important finding was that the effect of high number of children and low fSES was evident for women alone. This might be a reflection of cultural nuances related to being a sacrificing mother (not women) in a large family, or, due to cost burden from other sick members of the family, or, the difference in services covered under the medical insurance, or, greater indirect costs or higher insurance cost for women, etc. ${ }^{50}$ Also, it is seen that the willingness to pay for the medical services decrease with the family size in Iran. ${ }^{51}$

The only HL domain that was significantly related to MEDA was communication and decision-making skills, Table 3. This aspect has been infrequently examined, but those with poor HL are more likely to ask their physicians fewer questions about medical issues. ${ }^{52}$ The effect of poor patient-physician communication and verbal dominance can also be present, for instance,

My sister was hospitalized and was to be operated. I was worried and asked her physician many questions. He said why do you ask so many questions? I said I wanted to know about her disease. He said he did not have time to spend an hour to answer my silly questions. ${ }^{22}$

Similar difficulties in understanding HI and engaging with health-care providers are also present in highly developed countries. $^{53}$

Similarly, those with poor HL have a high risk of delaying their decision to seek medical care, and as a result, may experience negative health outcomes. ${ }^{54}$ For instance,

I did not seek information much. In fact I had not taken pregnancy seriously, and I was very optimistic. I thought it was not very important. When I faced with problems, I realized I should not have been so optimistic. ${ }^{37}$

Contrasting results are also evident in terms of HL and decision-making. ${ }^{52}$

Lastly, we had subjects with newly diagnosed pHTN and those with long duration of HTN, which may yield a different association of HL with MEDA. As is usually the case, the responses were based on self-reports, but we employed validated questionnaires and systematic procedures. There are other methods to measure adherence to treatments such as the Haynes-Sackett test; being the gold standard the count of the number of tablets. In addition, Cronbach's alpha of the Health Knowledge subscale (0.41) and the pFAS (0.65) were both low, which may be due to low number of questions, heterogeneous constructs, or poor inter-relatedness between items. ${ }^{55}$ In the original papers on the development of IHLQ ${ }^{20}$ 
and translation of $\mathrm{pFAS}^{23}$ the authors reported none and 0.88 , respectively, as Cronbach alpha for the scales. In our study, poor Cronbach alpha for both scales seems to be due to heterogeneous items and constructs of the scales, which need more investigations in future research. We collected essential socio-demographic variables, but both HL and MEDA may get affected by many other variables, for instance, living status, or, mental health status, etc. We included those with at least 30 years of age, although those who are less than this age are also at the risk of developing HTN. Moreover, as our main goal was to find associations between HL and MEDA, we ignored some important parameters like smoking, cardiac disease, stroke, and Body Mass Index in order to diminish the number of questions that we had to ask the patients. For future research, considerations on the role of such factors while studying the associations are recommended. Future research is suggested to explore gender as a moderator between HL and MEDA rather than stratifying the associations based upon gender. This would allow interpretation of the effect of HL on MEDA in one group (eg, men) compared to another (eg, women).

\section{Conclusions}

Based on a population-based work with sufficient sample from a low-middle income countries' context, we conclude that HL correlates with non-adherence on self-reported measures and intervention in HL may improve adherence among hypertensive subjects, particularly for men. For women, the number of children and family's socioeconomic status may also affect MEDA in addition to HL, albeit to a far lower degree. For both men and women, the focus needs to be on reducing the communication conflict because of difference in what patient's expect and require, and what health system currently provides. The association of HL with MEDA should be confirmed through interventional studies to help make HL a formal mitigating strategy for various public health goals.

\section{Ethics and Consent Statements}

We confirm that this study was conducted in accordance with the Declaration of Helsinki. Ethics approval was obtained from the Institutional review Board of the Tehran University of Medical Sciences (IR.TUMS.VCR.REC.1396.1012). The data collected in this study were only intended for internal use. The patients in this study signed a consent form, and data will be available per request.

\section{Funding}

No grant was received to conduct this study.

\section{Disclosure}

The authors report no conflicts of interest in this work.

\section{References}

1. Whelton PK, Carey RM, Aronow WS, et al. ACC/AHA/AAPA/ABC/ $\mathrm{ACPM} / \mathrm{AGS} / \mathrm{APhA} / \mathrm{ASH} / \mathrm{ASPC} / \mathrm{NMA} / \mathrm{PCNA}$ guideline for the prevention, detection, evaluation, and management of high blood pressure in adults: executive summary: a report of the American College of Cardiology/American Heart Association Task Force on Clinical Practice Guidelines. Circulation. 2017;2018(138):e426-e83.

2. James PA, Oparil S, Carter BL, et al. 2014 Evidence-based guideline for the management of high blood pressure in adults: report from the panel members appointed to the Eighth Joint National Committee (JNC 8). JAMA. 2014;311(5):507-520.

3. Fatani FN, AlSobaei RM, Alobodi NS, Alshehri ZH, Alrajih HA, Fallatah AA. Poor compliance to anti-hypertensive drugs among patients in Saudi Arabia. Indo Am J Pharm Sci. 2019;6:3752-3758.

4. Osterberg L, Blaschke T. Adherence to medication. $N$ Engl J Med. 2005;353:487-497. doi:10.1056/NEJMra050100

5. H F. Hypertension in the middle East. Lancet. 2012;380.

6. WHO. Adherence to Long-Term Therapies: Evidence for Action. Geneva: World Health Organization; 2003.

7. Nutbeam D. Defining and measuring health literacy: what can we learn from literacy studies? Int J Public Health. 2009;54(5):303-305. doi:10.1007/s00038-009-0050-x

8. Afshari M, Khazaei S, Bahrami M, Merati H. Investigating adult health literacy in Tuyserkan City. J Educ Com Health. 2014;1:48-55. doi: $10.20286 /$ jech-010248

9. Naser Ghasemi A, Peyman N, Tehrani H, et al. The relationship of health literacy with hypertension self-efficacy and general self-efficacy among schoolteachers. Mod Care J. 2018;15:e82983. doi:10.5812/modernc

10. McCleary-Jones V. Assessing nursing students' knowledge of health literacy. Nurse Educ. 2012;37:214-217. doi:10.1097/NNE.0b013e318262ead3

11. Veenker H, Paans W. A dynamic approach to communication in health literacy education. BMC Med Educ. 2016;16:280. doi:10. 1186/s12909-016-0785-z

12. Darvishpour J, Omidi S, Farmanbar R. The relationship between health literacy and hypertension treatment control and follow-up. Caspian J Health Res. 2016;1:1-8.

13. Samal D, Greisenegger S, Auff E, Lang W, Lalouschek W. The relation between knowledge about hypertension and education in hospitalized patients with stroke in Vienna. Stroke. 2007;38:1304-1308. doi:10.1161/01.STR.0000259733.43470.27

14. DiMatteo MR. Variations in patients' adherence to medical recommendations: a quantitative review of 50 years of research. Med Care. 2004;42:200-209. doi:10.1097/01.mlr.0000114908.90348.f9

15. Golboni F, Nadrian H, Najafi S, Shirzadi S, Mahmoodi H. Urbanrural differences in health literacy and its determinants in Iran: A community-based study. Aust J Rural Health. 2018;26:98-105. doi:10.1111/ajr.12378

16. Wong MCS, Tam WW, Cheung CSK, et al. Medication adherence to first-line antihypertensive drug class in a large Chinese population. Int $J$ Cardiol. 2013;167:1438-1442.

17. Ross S, Walker A, MacLeod MJ. Patient compliance in hypertension: role of illness perceptions and treatment beliefs. J Hum Hypertens. 2004;18:607-613. doi:10.1038/sj.jhh.1001721

18. Victor RG, Leonard D, Hess P, et al. Factors associated with hypertension awareness, treatment and control in Dallas County, Texas. Arch Intern Med. 2008;168:1285-1293. doi:10.1001/archinte.168. 12.1285

19. Kim J. Measuring the level of health literacy and influencing factors: targeting the visitors of a university hospital's outpatient clinic. J Korean Clin Nurs Res. 2011;17:27-34. 
20. Haghdoost A, Rakhshani F, Aarabi M, et al. Iranian Health Literacy Questionnaire (IHLQ): an instrument for measuring health literacy in Iran. Iran Red Crescent Med J. 2015;17:e25831. doi:10.5812/ircmj.17(5) 2015.25831

21. Morisky DE, Green LW, Levine DM. Concurrent and predictive validity of a self-reported measure of medication adherence. Med Care. 1986;24:67-74. doi:10.1097/00005650-198601000-00007

22. Koschack J, Marx G, Schnakenberg J, Kochen M, Himmel W. Comparison of two self-rating instruments for medication adherence assessment in hypertension revealed insufficient psychometric properties. J Clin Epidemiol. 2010;63:299-306. doi:10.1016/j. jclinepi.2009.06.011

23. Shokrvash B, Salehi L, Hariri Akbari M, et al. Social support and dairy products intake among adolescents: a study from Iran. $B M C$ Public Health. 2015;15:1078. doi:10.1186/s12889-015-2399-5

24. West SG, Finch JF, Curran P. Structural Equation Models With Nonnormal Variables: Problems and Remedies. 1995;56-75.

25. Meyers LS, Gamst G, Guarino AJ. Applied Multivariate Research: Design and Interpretation. Thousand Oaks, CA, US: Sage Publications, Inc; 2016

26. Culig J, Leppée M. From Morisky to Hill-bone; self-reports scales for measuring adherence to medication. Coll Antropol. 2014;38:55-62.

27. Abegaz TM, Shehab A, Gebreyohannes EA, Bhagavathula AS, Elnour AA. Nonadherence to antihypertensive drugs: A systematic review and meta-analysis. Medicine (Baltimore). 2017;96:e5641. doi:10.1097/MD.0000000000005641

28. Nafradi L, Galimberti E, Nakamoto K, Schulz PJ. Intentional and unintentional medication non-adherence in hypertension: the role of health literacy, empowerment and medication beliefs. J Pub Health Res. 2016;5:762-768.

29. Nations M, Firmo JO, Lima-Costa M, Uchôa E. Balking blood pressure "control" by older persons of Bambuí, Minas Gerais State, Brazil: an ethno-epidemiological inquiry. Cadernos Saúde Públ. 2011;27:378-389. doi:10.1590/S0102-311X2011001500008

30. Ko Y, Balasubramanian TD, Wong L, Tan ML, Lee E, Tang WE. Health literacy and its association with disease knowledge and control in patients with hypertension in Singapore. Int J Cardiol. 2013;168:116-117. doi:10.1016/j.ijcard.2013.08.041

31. Tehrani-Banihashemi S, Amirkhani MA, Haghdoost AA, Alavian S, Asgharifard H, Baradaran H. Health literacy and the influencing factors: a study in Five Provinces of Iran. Strides Dev Med Edu. 2007;4:1-9.

32. Ishikawa H, Kiuchi T. Association of health literacy levels between family members. Front Pub Health. 2019;7:169-175. doi:10.3389/ fpubh.2019.00169

33. Najafipour F, Mobasseri M, Yavari A, et al. Effect of regular exercise training on changes in HbA1c, BMI and VO2max among patients with type 2 diabetes mellitus: an 8-year trial. BMJ Open Diabetes Res Care. 2017;5:e00414. doi:10.1136/bmjdrc-2017-000414

34. Rowlands G, Protheroe J, Winkley J, Richardson M, Seed PT, Rudd R. A mismatch between population health literacy and the complexity of health information: an observational study. $\mathrm{Br} \mathrm{J} \mathrm{Gen}$ Pract. 2015;65:379-386. doi:10.3399/bjgp15X685285

35. Berens E, Vogt D, Messer M, Hurrelmann K, Schaeffer D. Health literacy among different age groups in Germany: results of a cross-sectional survey. BMC Pub Health. 2016;16:1151-1159. doi:10.1186/s12889-016-3810-6

36. Hsi YY, Chen CY, Lee MB. Life quality of post-myocardial infarction patients: influence of personal variables on coping. J Formos Med Assoc. 1990;89:149-155.

37. Nikbakht-Nasrabadi A, Sabzevari S, Negahban-Bonabi T. Iranian women's experiences of health information seeking barriers: a qualitative study in Kerman. Iran Red Cres Med J. 2015;17:251-256. doi:10.5812/ircmj.25156
38. Wang MP, Viswanath K, Lam TH, Wang X, Chan SS. Social determinants of health information seeking among Chinese adults in Hong Kong. PLoS One. 2013;8:1371-1376.

39. Gavgani VZ. Health information need and seeking behavior of patients in developing countries' context; an Iranian experience. 1st ACM International Health Informatics Symposium; 2010.

40. Dastjerdi M. The case of Iranian immigrants in the greater Toronto area: a qualitative study. Int $J$ Health Equity. 2012;11:9-11. doi:10.1186/1475-9276-11-9

41. Behnood-Rod A, Rabbanifar O, Pourzargar P, et al. Adherence to antihypertensive medications in Iranian patients. Int $J$ Hyperten. 2016;2016:1-7. doi:10.1155/2016/1508752

42. Arabzadeh S, Sadeghi M, Rabiei K, Sarrafzadegan N, Taheri L, Golshahi J. Determinants of uncontrolled hypertension in an Iranian population. ARYA Atheroscler. 2014;10:25-31.

43. Aşılar RH, Gözüm S, Çapık C, Morisky DE. Reliability and validity of the Turkish form of the eight-item morisky medication adherence scale in hypertensive patients. Anad Kardiyol Derg. 2014;14:692-700. doi:10.5152/akd.2014.4982

44. Lee JK, Grace KA, Foster TG. How should we measure medication adherence in clinical trials and practice? Therap Clin Risk Man. 2007;3:685-690.

45. Delgado JM, Ruppar TM. Health literacy in older latinos with heart failure: a systematic review. J Cardiovasc Nurs. 2017;32:125-134. doi:10.1097/JCN.0000000000000314

46. Hall E, Lee SY, Clark PC, Perilla J. Social ecology of adherence to hypertension treatment in latino migrant and seasonal farmworkers. J Transcult Nurs. 2016;27:33-41. doi:10.1177/1043659614524788

47. Wannasirikul P, Termsirikulchai L, Sujirarat D. Health literacy, medication adherence, and blood pressure level among hypertension older adults treated at primary health care centers. Southeast Asia J Trop Med Pub Health. 2016;47:109-120.

48. Ragbaoui Y, Nouamou I, Hammiri A, Habbal R. Predictive factors of medication adherence in patients with chronic heart failure: Morocco's experience. Pan Afr Med J. 2017;26:115. doi:10.11604/ pamj.2017.26.38.10312

49. Ickovics JR, Meade CS. Adherence to antiretroviral therapy among patients with HIV: a critical link between behavioral and biomedical sciences. $J$ Acquir Immune Defic Syndr. 2002;31:S98-102. doi:10.1097/00126334-200212153-00002

50. Mehrdad R. Health system in Iran. J Med Assoc Japan. 2009;52:69-73.

51. Nosratnejad SRA, Rashidian A, Mehrara M, Akbari Sari A, Mahdavi G, Moeini M. Willingness to pay for the social health insurance in Iran. Global J Health Sci. 2014;6:154-163. doi:10.5539/gjhs.v6n5p154

52. Aboumatar HJ, Carson KA, Beach MC, Roter DL, Cooper LA. The impact of health literacy on desire for participation in healthcare, medical visit communication, and patient reported outcomes among patients with hypertension. J Gen Intern Med. 2013;28:1469-1476. doi:10.1007/s11606-013-2466-5

53. Bo A, Friis K, Osborne RH, Maindal HT. National indicators of health literacy: ability to understand health information and to engage actively with healthcare providers - a population-based survey among Danish adults. BMC Pub Health. 2014;22:1095-1099. doi:10.1186/ 1471-2458-14-1095

54. Hibbard JH, Greene J. What the evidence shows about patient activation: better health outcomes and care experiences; fewer data on costs. Health Aff. 2013;32:207-214. doi:10.1377/hlthaff.2012.1061

55. Tavakol M, Dennick R. Making sense of Cronbach's alpha. Int J Med Educ. 2011;27:53-55. doi:10.5116/ijme.4dfb.8dfd 


\section{Publish your work in this journal}

Vascular Health and Risk Management is an international, peerreviewed journal of therapeutics and risk management, focusing on concise rapid reporting of clinical studies on the processes involved in the maintenance of vascular health; the monitoring, prevention and treatment of vascular disease and its sequelae; and the involvement of metabolic disorders, particularly diabetes. This journal is indexed on PubMed Central and MedLine. The manuscript management system is completely online and includes a very quick and fair peerreview system, which is all easy to use. Visit http://www.dovepress. com/testimonials.php to read real quotes from published authors. 